\title{
Chemistry of Sanitation
}

\author{
By A. M. Buswell
}

ChIEF, Imilnois State Water Survey, Urbana, Iliminois

\section{Production of Potable Water}

$\mathrm{W}$ I'TH THE development of quantitative bacteriological technic, chemical tests for determining the sanitary quality of water lost much of their former importance. Because of increasing necessity for the use of surface supplies, all of which are more or less subject to pollution, the main question has become one of purification rather than of a test for freedom from infection, and it should be remembered that purification involves a great deal more than disinfection. Disease germs can be killed or got rid of with comparative ease, but tastes, odors, and turbidity must also be removed in order to produce a potable water.

Water purification is, therefore, an essential chemical process and it is along the line of the investigations of the reactions involved and methods for their control that the water chemist is again coming into his own. Though it is possible at the present time to produce a potable water from almost any source, no matter how polluted, yet there is room for improvement of the product as well as of the process. Furthermore, the art is at present ahead of the theory. We can purify water with reasonable success, but we do not understand the mechanism of the reactions involved. "Who but the chemist is to fix the proper value for the dose of chemicals?" said Professor Mason 1,* seven years ago, and we might add, "Who but the chemist can investigate the complicated reactions of these chemicals?"

The following steps represent what may fairly be considered as present standard practice in purification of municipal surface supplies for general domestic use: coagulation with aluminium sulfate or ferrous sulfate; sedimentation; rapid filtration through sand; and, finally, disinfection with chlorine. Some of the earlier "slow sand" filters are still in use, especially in Europe. In some cases chlorination without filtration is used as a more or less temporary measure and in a few instances filtration without chlorination is regarded as sufficient. Softening or iron removal is sometimes attempted; but in general such treatment is left to the private or industrial consumers.

The relation of $\mathrm{pH}$ to precipitation of $\mathrm{Al}(\mathrm{OH})_{3}$ has probably been the most extensively investigated problem in the last few years. Practice had been to add lime to waters which after alum treatment showed a residuum of less than $20 \mathrm{p} . \mathrm{p} . \mathrm{m}$. of $\mathrm{CaCO}_{3}$ (alkalinity). But Wolman and Hannan' showed not only that the addition of lime was unnecessary in most cases but that in some instances the addition of small amounts of acid favored precipitation. At the same time Buswell and Greenfield ${ }^{3}$ investigated the various reactions of water purification and water softening, following the course of the reactions with the hydrogen electrode. A committee of the American Water Works Association, R. S. Weston, chair-

* Numbers in text refer to Bibliography at end of this article. man, with the aid of a number of filter plant operators, compiled this year a considerable amount of data which will be published in the journal of that society. Clark and Theriault ${ }^{4}$ report that hydrogen electrode experiments have shown that equilibria in aluminium solutions with the solid phase (aluminium hydroxide?) present are complex. The peculiarities nullify the value of methods previously used to estimate the isoelectric point. By taking advantage of these peculiarities the isoelectric point has been found to lie between $\mathrm{pH} 5.5$ and 6.0. Experiments on time of flocculation have shown minimum time at or near $\mathrm{pH}$ 5.5. An empirical equation has been found relating time for first appearance of floc and $\mathrm{pH}$ under uniform sets of laboratory conditions. Time of flocculation is also a function of circulation, and rough relations have been found whereby small vessel experiments may be extrapolated to large volume conditions.

Buswell and Edwards ${ }^{5}$ have shown that the unprecipitated aluminium in treated water is less than is ordinarily found in untreated natural waters even when the $\mathrm{pH}$ is far from the optimum. This should quiet the fears, expressed occasionally in medical circles, of the physiological effect of the "alum" used in water purification. While the $\mathrm{pH}$ determination has not proved the panacea some would have led us to expect, it has already proved its usefulness in the operation of certain filter plants, notably the one at Baltimore. ${ }^{6}$ The colloidal phase of the problem is generally recognized; yet, with the exception of the work of Catlett ${ }^{7}$ and of O. M. Smith ${ }^{8}$ and some theoretical proposals by Pirnie, little progress has been made along that line.

While the role of oxygen in causing corrosion has long been recognized, several articles ${ }^{10}$ have recently appeared describing various devices for preventing corrosion by means of "deoxidation." These are in general of two types: (1) Filtering the water over iron or other metal turnings to "deoxidize" it, or (2) boiling out the dissolved gases. In some cases a combination of the two is used. Tillmans and Heublein ${ }^{11}$ and later Kolthoff ${ }^{12}$ have shown that, as would be predicted from the mass law, the presence of $\mathrm{Ca}\left(\mathrm{HCO}_{3}\right)_{2}$ lessens the solvent action of $\mathrm{H}_{2} \mathrm{CO}_{3}$ on $\mathrm{CaCO}_{3}$. The amount of $\mathrm{CaCO}_{3}$ which a water will dissolve is a measure of the "aggressive" $\mathrm{CO}_{2}$ which is a different numerical value from "free" $\mathrm{CO}_{2}$.

Don' $\mathrm{s}^{13}$ recent investigation of the adsorption of ammonium salts in sand filters recalls the much earlier work of Chick $^{14}$ on the same subject but from the standpoint of sewage treatment. The cause of surface shrinkage in filters has been attributed to adsorption..$^{15}$

A symposium on tastes and odors was held at the last convention ${ }^{4}$ of the American Water Works Association. Chlorine may be noticeable if present in excess or it may produce organic compounds which cause a "chemical" or "iodoform" taste. British operators recommend "antichlors" for the former and $\mathrm{KMnO}_{4}$ for the latter. 
The most serious recent trouble due to tastes was that produced by Synuria in New York City ${ }^{16}$ supply. This taste was removed by treating with an excess of $\mathrm{Cl}_{2}$. Another case is recorded in which an attendant attempted to dislodge by force a specimen of Mephitis mephitis (vulgarly known as skunk) which had perched on the water intake.

The obvious disadvantage of waiting 24 to $48 \mathrm{hrs}$. for bacteriological results to tell whether or not chlorine treatment has been sufficient, has led to the immediate popularity of the chemical "excess chlorine" test of Enslow and Wolman,"17 which can be read within half an hour. The study of filter plant loading by Streeter ${ }^{18}$ has thrown considerable light on what may be expected from various purification plants.

No radical changes have taken place in the field of matter softening since the introduction of zeolites 10 or 15 yrs. ago. Comparatively little has been published on the zeolite base exchange ${ }^{19}$ reactions outside the patent literature, but it is now apparent that the power to exchange bases is possessed by a large number of "alumino silicate" compounds.

Indican ${ }^{20}$ as an indicator of pollution has been suggested. Various modifications of the hardness tests ${ }^{21}$ have recently been proposed. Several attempts to develop a delicate test for phenols ${ }^{22}$ in water have met with questionable success, apparently because of the interference of natural coloring matter. Scheringa ${ }^{23}$ has recently investigated the $\mathrm{N}_{2}$ cycle in water, and Nichols ${ }^{24}$ has made a new study of the significance of nitrates.

The A. P. H. A. standard methods of water and sewage analysis have been revised with the coöperation of a committee from this SocIETY and are to be published in the near future. Public Health Engineering Abstracts, issued weekly by the "Treasury Department Public Health Service, covers American and foreign literature. The American Water Works Association has recently included an abstract department in its journal. Additional articles ${ }^{25}$ of importance are mentioned in the Bibliography, page 842 .

\section{Stream Pollution}

Probably the most important advance in this field has been along the line of analytical methods. The older tests, oxygen sonsumed from $\mathrm{KMnO}_{4}$ and solids lost on ignition, were admittedly empirical and since there was little uniformity of technic among different workers there was small basis for comparing their results. No less than five different methods for the oxygen consumed from. $\mathrm{KMnO}_{4}$ are given by various authoritative textbooks. The estimation of the degree of pollution from the forms of combined nitrogen has not been found feasible. The present method, originally described by the Royal Commission on Sewage .Disposal, ${ }^{26}$ measures the amount of dissolved oxygen required to satisfy or "stabilize" the organic matter in the sample. This is accomplished by diluting the sample with an amount of aerated distilled or tap water sufficient to contain an excess of dissolved oxygen and then titrating the residual oxygen after a period of incubation $(1,2$, or 5 days) at constant temperature (usually $20^{\circ} \mathrm{C}$.). From the titration and the length of incubation the "biochemical oxygen demand" is calculated, or the results may be expressed as "1-day demand," "2-day demand," or "5-day demand." When first proposed this method met with some opposition in this country owing to the frequency of erratic results, and the method was not included in the 1917 edition of Standard Methods of A. P. H. A. The method had much to recommend it, however, on account of its similarity to natural conditions and was adopted for stream jollution investigations by the U. S. Public Health Service. Largely through the efforts of this Service ${ }^{27}$ the sources of most of the troubles have been found and a satisfactory technic: worked out, which will appear in the new edition of Standard Methods.

The results of the extensive investigation of the Ohio River by the U. S. Public Health Service are to be published in the near future. The report will contain much information on methods of stream study and the course of the autopurification reactions. The same organization has been making a study of the Illinois River, in which opportunity has been afforded for checking and improving their investigational methods. We may expect considerable improvement in the "tools" of sanitary chemistry as well as voluminous data on the particular problems studied as the result of these investigations.

A symposium ${ }^{28}$ on "Stream Pollution and Sewage Disposal" held at a meeting of the American Society of Civil Engineers in New York in November 1921, together with the discussion which followed, contains considerable information of a chemical nature. Donaldson ${ }^{29}$ has reported on the relation of coal and oil, tannery, paper, and various other industrial wastes to water supplies. The limit of 200 to 400 p. p. m. of chlorides which has been set ${ }^{29,30}$ on the allowable pollution from oil-well wastes and sea water seems to the writer to be unjustifiably low. Several cases of ground-water supplies containing 1000 p. p. m. or more of chlorides could be cited, and there is evidence that vegetation ${ }^{31}$ and cattle will tolerate 2000 to 3000 parts. Gould ${ }^{32}$ has discussed the oxygen requirement of New York harbor and the various sources from which this demand may be met. He concludes that surface aeration is the principal source of $O$, while Purdy in the discussion calls attention to the importance of microörganisms and aquatic plants. Streeter in discussing the same paper calls attention to the fact that turbulence must be depended upon for rapid aeration.

\section{Sewage Purification}

Activity in conserving nitrogen has been largely devoted to the development of the activated sludge process which is discussed in a separate article. Richards and Weekes ${ }^{\mathbf{3}}$ have proposed straw filters for sewage disposal and find that the bacterial growths which occur, fix ammoniacal and nitrate nitrogen. After a time the straw is replaced and, because of the nitrogen accumulated in the bacterial growths, the used straw is good for fertilizer.

Ardern ${ }^{34}$ has discussed sewage disposal with reference to colloid chemistry, and he gives an excellent summary of the various theories of sewage purification together with valuable lists of references. He favors a middle ground between the biochemical and colloidal theories.

$\mathrm{Cox}^{35}$ considers that the microbial growths on trickling filters are of greater importance than they are usually deemed to be. He gives lists of organisms found and concludes that the flora and fauna of the filter determine the biochemical reactions produced. Thompson ${ }^{36}$ has made a similar study of trickling filter biology, more especially with reference to activity of enzymes which he proved were produced.

Wagenhals ${ }^{37}$ concludes from an extensive engineering and chemical survey of sewage treatment plants that the Gooch crucible determination of suspended matter and the five-day biochemical oxygen demand at $20^{\circ}$ are the best tests for determining the efficiency of sewage treatment plants. The paper contains considerable chemical data. Buswell and Weinhold ${ }^{38}$ call attention to advantages of the ultra filter over the Gooch crucible, viz., portability, speed, and the fact that it may be calibrated to give a notion of the size of colloidal particles. Mohlman and Pearse ${ }^{39}$ have reviewed the various methods for estimating colloids and have suggested the use of the nephelometer. 